\title{
BRCA1 genomic deletions are major founder mutations in Dutch breast cancer patients
}

Anne Petrij-Bosch ${ }^{1}$, Tamara Peelen ${ }^{1}$, Margreethe van Vliet ${ }^{1}$, Ronald van Eijk ${ }^{2}$, Renske Olmer ${ }^{1}$, Marion Drüsedau ${ }^{1}$, Frans B.L. Hogervorst ${ }^{3}$, Sandra Hageman ${ }^{3}$, Petronella J.W. Arts ${ }^{4}$, Marjolijn J.L. Ligtenberg ${ }^{4}$, Hanne Meijers-Heijboer $^{5}$, Jan G.M. Klijn ${ }^{6}$, Hans F.A. Vasen ${ }^{7}$, Cees J. Cornelisse ${ }^{2}$, Laura J. van't Veer ${ }^{3}$, Egbert Bakker ${ }^{1}$, Gert-Jan B. van Ommen ${ }^{1}$ \& Peter Devilee ${ }^{1,2}$

\section{Nature Genet. 17, 341-345 (1997).}

There is an error in the abstract on page 341. A 3,835-bp Alu-mediated deletion encompassing exon 13 was detected in 4 of 170 research familes. This is correctly stated elsewhere in the text and this error does not affect the conclusions of the paper. We regret this error.

\section{Early diabetes and abnormal postnatal pancreatic islet development in mice lacking Glut-2}

Marie-Thérèse Guillam ${ }^{1}$, Edith Hümmler ${ }^{1}$, Elisabeth Schaerer ${ }^{1}$, J.-Y. Wu ${ }^{2}$, Morris J. Birnbaum ${ }^{3}$, Friedrich Beermann ${ }^{4}$, Andrea Schmidt ${ }^{4}$, Nathalie Dériaz ${ }^{1} \&$ Bernard Thorens $^{1}$

Nature Genet. 17, 327-330 (1997).

Due to an error on our part, Table 1 (below) was not printed in the text, and Table 2 was presented as Table 1 . We regret this error.

\begin{tabular}{|c|c|c|c|}
\hline \multicolumn{4}{|c|}{$\begin{array}{l}\text { Table 1 Plasma metabolite and hormone levels } \\
\text { in 10-15 day old }+/+,+/- \text { and }-t-\text { mice (13) }\end{array}$} \\
\hline $\begin{array}{ll}\text { Glucose }(\mathrm{mM}) & \text { male } \\
& \text { female } \\
\text { Insulin ( } \mu \text { Units/ml) } & \\
\text { Glucagon }(\mathrm{pg} / \mathrm{ml}) & \\
\text { NEFA }(\mu \mathrm{m}) \\
\beta \text {-Hydroxybutrate (mg/dl) } \\
\text { Lactate (mM) } \\
\text { Osmolarity (msmol) }\end{array}$ & $\begin{aligned}+1+ & + \\
508 & \pm 0.5 \\
7 & \pm 0.7 \\
14.6 & \pm 2.6 \\
115.08 & \pm 38.7 \\
507.4 & \pm 17.7 \\
9.6 & \pm 1.6 \\
2.53 & \pm 0.2 \\
293.33 & \pm 3.7\end{aligned}$ & $\begin{aligned}+/- & \\
5.49 & \pm 0.2 \\
6.08 & \pm 0.3 \\
11.83 & \pm 2.0 \\
88.63 & \pm 10.7 \\
489.35 & \pm 25.5 \\
8.5 & \pm 1.7 \\
2.4 \pm 0.2 & \\
290.33 & \pm 2.3\end{aligned}$ & $\begin{array}{c}-1- \\
11.57 \pm 0.9 \\
12.04 \pm 1.0 \\
11.58 \pm 1.6 \\
399.71 \pm 78.5 \\
936.94 \pm 42.4 \\
51.4 \pm 8.1 \\
2.2 \pm 0.3 \\
416.25 \pm 29.7\end{array}$ \\
\hline \multicolumn{4}{|c|}{ Glucose and ketones levels in urine of 10-15 day old $+1+,+l-$ and $-1-$ Glut2 mice } \\
\hline $\begin{array}{l}\text { Glucose (mM) } \\
\text { Ketone (mM) }\end{array}$ & $\begin{array}{l}+l+ \\
\text { nd } \\
\text { nd }\end{array}$ & $\begin{array}{l}+1- \\
\text { nd } \\
\text { nd }\end{array}$ & $\begin{array}{l}-1 \\
>111 \\
1.5-16\end{array}$ \\
\hline
\end{tabular}

